\title{
Surface modification of polysulfone based hemodialysis membranes with layer by layer self assembly of polyethyleneimine/alginate-heparin: a simple polyelectrolyte blend approach for heparin immobilization
}

\author{
Filiz Yasar Mahlicli - Sacide Alsoy Altinkaya
}

Published online: 7 November 2012

(c) Springer Science+Business Media New York 2012

\begin{abstract}
This study intends to improve blood compatibility of polysulfone (PSF) membranes by generating a nonthrombogenic surface through heparin immobilization. To achieve this task, the support membrane prepared from a blend of PSF and sulfonated polysulfone (SPSF) was modified with layer by layer (LBL) deposition of polyethyleneimine (PEI) and alginate (ALG) and heparin blended with ALG was immobilized only on the outermost surface of the LBL assembly. The results have shown that the adsorption of human plasma proteins and platelet activation on the LBL modified membranes decreased significantly compared with the unmodified PSF and PSFSPSF blend membranes. Furthermore, blending ALG with a small amount of heparin remarkably prolonged the APTT values of heparin free PEI/ALG coated membranes. It is envisaged that the use of a blend of HEP and ALG only in the terminating layer of the LBL assembly can be an economical and alternative modification technique to create nonthrombogenic surfaces.
\end{abstract}

\section{Introduction}

Extracorporeal thrombosis is a major problem of hemodialysis operation leading to embolism and infarction. To prevent this problem, blood anticoagulant heparin is usually injected during hemodialysis. However, using large amount of heparin can increase the risk of abnormal bleeding and heparin induced thrombocytopenia. In recent

F. Y. Mahlicli · S. A. Altinkaya ( $\square)$

Department of Chemical Engineering, Izmir Institute of

Technology, Gulbahçe Koyu, 35430 Urla, Izmir, Turkey

e-mail: sacidealsoy@iyte.edu.tr years, researchers focused on producing nonthrombogenic materials to provide heparin-free hemodialysis. The most commonly used approach is to mimic endothelial cell layer by heparin immobilization. The beneficiary effect of heparin coatings on the membranes has been reported by many authors both in vitro [1-9] and in vivo [10-15]. For example, Cheung et al. [1] observed that complement activation induced by hemodialysis can be modulated with heparin immobilized cellulose acetate membrane. Baumann and Kokott [2] immobilized endothelial cell surface heparin sulfate (ESHS) on polysulfone (PSF), polycarbonate and polyurethane membranes and they found that the coating of these membranes by ESHS allows to generate surfaces resistant to platelet adhesion and have no effects on complement and intrinsic coagulation cascade activation. Yang and Lin [3, 4] and Lin et al. [5] covalently bonded chitosan/heparin conjugate onto the surface of PAN and PSF membranes and they reported improved biocompatibility of these membranes by evaluating coagulation time, plasma protein adsorption capacity and platelet adhesion [1-5]. Zhu et al. [6], Jiang et al. [7] and Huang et al. $[8,9]$ also improved blood compatibilities of the poly(vinylidene fluoride), polyethylene (PE) and PSF membranes by covalent attachment of heparin [6-9]. In vivo tests carried out with commercial hemodialysis membranes, AN69 ST, HEMOPHAN and EVODIAL showed that it is possible to reduce systemic administration of heparin through its immobilization on these membranes [10-15]. On the other hand, one clinical study reported that heparin coated AN69 ST membrane does not reduce clotting during hemodialysis when compared to a conventional PSF filter [16]. In most of these studies, heparin was covalently attached to the surfaces, on the other hand, ionic binding was also used for immobilization [10, 12-14, 16]. Recently, the layer by layer self-assembly (LBL) technique 
has emerged as a versatile, gentle and easy surface modification method for immobilization of functional molecules. The assembly process can be conducted in an aqueous solution under mild ambient conditions which minimize the loss in the activity of biological agents due to attachment on a surface. Electrostatic interactions are most often used to drive multilayer assembly, however, other interactions such as hydrogen bonding, hydrophobic interactions and molecular recognition can also be applied for constructing the assembly [17]. The LBL method can be utilized for all types of multifunctional and mutually interacting species and the strength of interactions between interacting species can be easily adjusted to minimize desorption of the functional molecules on the surface of the assembly. The method was used to improve biocompatibility of blood-contacting materials. For example, platelet adhesion/activation and leukocyte adhesion on polyethersulfone hemodialysis membrane were significantly reduced with the LBL deposition of heparin and albumin on the surface of this membrane [18].

This study intends to improve hemocompatibility of PSF based hemodialysis membranes through heparin (HEP) immobilization. To achieve this task, first the support membrane was prepared from a blend of PSF and sulfonated polysulfone (SPSF) and modified with layer by layer (LBL) deposition of polyethyleneimine (PEI) and alginate (ALG). Then, heparin was immobilized only on the outermost surface of the LBL assembly by blending with ALG. In previous studies, heparin was used alone to adsorb on positively charged polyelectrolytes for each alternating layer. In our study, small amount of HEP was blended with another polyanion, ALG, to form the outermost layer of the assembly. The intermediate layers were prepared with the alternate deposition of the PEI and heparin free ALG. The scientific motivation of this work is to investigate the anticoagulant activity and biological properties of HEP when blended with another polyanion, ALG. We compare the hemocompatibilities of the PSF and polysulfonesulfonated polysulfone (PSF-SPSF) membranes with those of the corresponding membranes modified with PEI/ALG and PEI/ALG-HEP coatings. The blood compatibilities of fabricated membranes were evaluated in terms of amount of adsorbed plasma proteins, the activated partial thromboplastin time (APTT), platelet adhesion, activation and cytotoxicity on blood cells. In addition, the transport, structural and mechanical properties of the membranes were also characterized. To the best of our knowledge, this is the first study which investigates the heparin immobilization on the PSF based hemodialysis membranes with the LBL assembly. In addition, in previous studies the benefit of blending heparin with another polyanion to improve hemocompatibility of the hemodialysis membranes was not illustrated.

\section{Materials and Methods}

\subsection{Materials}

Polysulfone with a molecular weight of $26,000 \mathrm{~g} \mathrm{~mol}^{-1}$, 1-2 dichloroethane, chlorosulfonic acid, sodium dodecylsulfate (SDS) were purchased from Aldrich, 1-methyl-2pyrrolidone (NMP) with a purity of $\gg 98 \%$ and micro BCA protein assay reagent kit were purchased from Fluka and Thermoscientific, respectively. Heparin, bovine serum albumin (MW 65000), urea, vitamin B12, lysozyme were all supplied by Sigma. Cell viability kits, thiazole orange (TO) and propidium iodide (PI), and the monoclonal antibodies, PAC1, FITC and CD62 PE, which were used for determination of platelet activation were purchased from Becton-Dickinson Immunocytometry Systems. $\mathrm{H}_{2} \mathrm{NaPO}_{4}$ and $\mathrm{Na}_{2} \mathrm{HPO}_{4}$ used for preparing buffer solutions were obtained from Fluka and Riedel, respectively. Water was distilled ion-exchanged water. Whole blood was taken from a healthy single donor and the ethics committee approval for the experiments with blood cells was obtained.

\subsection{Preparation of the membranes}

The conventional PSF has no functional groups and charges, thus, it was first modified by sulfonation to induce negatively charged groups $\left(\mathrm{SO}_{3}{ }^{-}\right)$before preparing the support membrane [19]. To prepare the PSF and PSF-SPSF blend membranes, a solution of $20 \mathrm{wt} \%$ of PSF or $10 \mathrm{wt} \%$ of PSF and $10 \mathrm{wt} \%$ of SPSF in $N$-methyl pyrrolidone was cast onto a $10 \times 24 \mathrm{~cm}$ glass substrate, respectively with the aid of an automatic film applicator (Sheen Instrument Ltd., model number: $1133 \mathrm{~N}$ ) at a speed of $100 \mathrm{~mm} \mathrm{~s}^{-1}$. The initial thickness of the cast film was adjusted by a four sided applicator with a gap size of $150 \mu \mathrm{m}$. Following casting, the support was transferred into an environmental chamber (Angelantoni Industrie, Italy, Challenge Series, model number: $\mathrm{CH} 250$ ) in which the solution was dried for 2 min under $25{ }^{\circ} \mathrm{C}$ temperature and $40 \%$ relative humidity. Then, it was immediately immersed in a coagulation bath for $18 \mathrm{~h}$, and rinsed with pure water for $1 \mathrm{~h}$. The membranes were allowed to dry further for a period of $72 \mathrm{~h}$ in a vacuum oven maintained at $100{ }^{\circ} \mathrm{C}$. They were then kept in a desiccator until their use.

The LBL assembly was formed on the negatively charged PSF-SPSF blend membrane. For this purpose, this membrane was first dipped in a $0.1 \mathrm{mg} \mathrm{ml}^{-1}$ of cationic macromolecule, PEI solution for $10 \mathrm{~min}$. The $\mathrm{pH}$ of the PEI solution was adjusted by $\mathrm{HCl}$ to a value of 8 , under its isoelectric point, to obtain a sufficiently protonated form, hence, to ensure its strong bonding on the negatively charged membrane surface through electrostatic attraction. 
Table 1 Codes of the unmodified and modified PSF membranes prepared

\begin{tabular}{lllll}
\hline $\begin{array}{l}\text { Membrane } \\
\text { code }\end{array}$ & $\begin{array}{l}\text { \# of } \\
\text { bilayer }\end{array}$ & $\begin{array}{l}\text { Polyanion type } \\
\text { in the middle } \\
\text { layers }\end{array}$ & $\begin{array}{l}\text { Polyanion } \\
\text { type in the } \\
\text { last layer }\end{array}$ & $\begin{array}{l}\text { Heparin concentration } \\
\text { in ALG-HEP } \\
\text { mixture (wt } \%)\end{array}$ \\
\hline PSF & 0 & - & - & - \\
PSF-SPSF & 0 & - & - & - \\
PEI/ALG-1b & 1 & ALG & ALG & 0 \\
PEI/ALG-5b & 5 & ALG & ALG & 0 \\
PEI/ALG-HEP-15-1b & 1 & ALG & ALG-HEP & 15 \\
PEI/ALG-HEP-15-5b & 5 & ALG & ALG-HEP & 15 \\
PEI/ALG-HEP-45-1b & 1 & ALG & ALG-HEP & 45 \\
PEI/ALG-HEP-45-5b & 5 & ALG & ALG-HEP & 45 \\
PEI/ALG-HEP-100-1b & 1 & ALG & HEP & 100 \\
PEI/ALG-HEP-100-5b & 5 & ALG & HEP & 100 \\
\hline
\end{tabular}

To remove excessive PEI on the surface of the selfassembled layer, the membrane was rinsed with $500 \mathrm{ml}$ water for $10 \mathrm{~min}$ and then immersed in a $1 \mathrm{mg} \mathrm{ml}^{-1}$ of ALG solution at $\mathrm{pH} 7.4$ and $4{ }^{\circ} \mathrm{C}$ for $24 \mathrm{~h}$. Loosely-bound ALG was washed away under same conditions as described above. The dipping in alternating PEI and ALG solutions and rinsing after each removal were repeated five times to build intermediate layers of multilayer assembly on the support membrane. Heparin was immobilized only on the outermost layer of this assembly by blending with ALG at a concentration of 15 and $45 \mathrm{wt} \%$. The preparation conditions and codes of the membranes prepared are listed in Table 1.

\subsection{Surface characterization}

Contact angle measurements for distilled water were carried out with Attension Optical tensiometer by means of a horizontal microscope, equipped with a video camera which is connected to a computer. The volume of liquid drop varied between 3 and $5 \mu \mathrm{l}$. The contact angle was calculated from the droplet screen image. Each reported contact angle measurement represents an average value of fifteen separate drops on different areas of the membranes obtained from three different batches.

In order to identify the change in surface charge of the membrane due to polyelectrolyte deposition, the specific staining of the membrane was used. The negatively charged groups (carboxyl, hydroxyl and sulfonate groups) on the membrane can form complexes with toluidine blue $\mathrm{O}$ dye at $\mathrm{pH} 10$ and the positively charged groups (amine groups) with congo red at $\mathrm{pH}$ 7. The staining was performed by dipping the membranes in a $30 \mathrm{ppm}$ solution of the dye dissolved in its associated solvent for ca. $30 \mathrm{~min}$, followed by washing the sample with its solvent until the solvent became colorless [3]. The amount of the charged groups on the membranes stained with toluidine blue $\mathrm{O}$ and congo red was determined spectrophotometrically in visible region (Aventes-Avemouse62). Intensity of each color resulting from adsorption of dyes on the membranes was reported as an average of ten measurements.

The layer-by-layer deposition of polyelectrolytes was followed by attenuated total reflectance Fourier transform infrared spectroscopy (ATR-FITR) (64 scans, $4 \mathrm{~cm}^{-1}$ resolution, wavenumber range 4,000-550 $\mathrm{cm}^{-1}$ ) measurements. Aqueous solutions of PEI and ALG-HEP were prepared in the same manner as the multilayer dipping solutions and each solution was cast onto a ZnSe substrate and dried to leave a pure polymer film for FTIR characterization.

To determine the surface roughness of the membranes, a topographical map of the membrane surfaces was obtained with atomic force microscopy (AFM) on a Nanomagnetics Instrument model. $5 \times 5 \mu \mathrm{m}$ surface was scanned with $512 \times 512$ pixel resolution using a silicon tip attached to a cantilever, while maintaining a constant force between the tip and the sample.

The bulk morphology of the membranes was examined by scanning electron microscopy (SEM) on a FEI-Quanta 250 FEG model. The samples were coated with gold using a Magnetron Sputter Coating Instrument.

\subsection{Protein adsorption experiments}

Protein adsorption experiments were performed with (i) blood plasma proteins obtained from $50 \%$ platelet poor plasma (PPP) (ii) model protein, bovine serum albumin (BSA). The membranes $(1.5 \times 1.5 \mathrm{~cm})$ equilibrated in $0.05 \mathrm{M}, \mathrm{pH} 7.4$ phosphate buffer at $37{ }^{\circ} \mathrm{C}$ for $15 \mathrm{~h}$, were first placed onto a 24 -well plate. $1.0 \mathrm{ml}$ of protein solution (PPP or BSA solution with a concentration of $4.5 \mathrm{mg} \mathrm{ml}^{-1}$ ) was poured onto membranes and allowed to remain at $37{ }^{\circ} \mathrm{C}$ for $1 \mathrm{~h}$. After rinsing three times with PBS, they were removed from the well plate and rinsed again sufficiently 
with $50 \mathrm{ml}$ of PBS in order to remove loosely-bond protein. Each membrane sample treated with protein was placed into a glass bottle containing $1 \mathrm{wt} \%$ aqueous solution of SDS and shaken $(150 \mathrm{rpm})$ in a shaking bath for $3 \mathrm{~h}$ at room temperature to detach the adsorbed protein on the surface. In order to take into account an interference which may be caused by SDS, membrane samples not treated with protein was used as a proper control. A protein analysis kit (Micro BCA protein assay reagent kit, \#23235, Pierce, Rockford, IL, USA) based on the bicinchoninic acid (BCA) method was used to determine the protein concentration in the SDS solution. The absorbance of the solution at $562 \mathrm{~nm}$ was measured by a spectrophotometer (Perkin Elmer Model No: Lambda 45). The fresh blood collected with citrated tubes from healthy volunteer was centrifuged at 2,800 rpm for $15 \mathrm{~min}$ at room temperature to obtain platelet poor plasma.

\subsection{Platelet and blood cell adhesion and activation}

In order to analyze the platelet activation, unmodified and modified PSF membranes were incubated with acid citrate dextrose (ACD)-whole blood at $37{ }^{\circ} \mathrm{C}$ for $25 \mathrm{~min} .5 \mu \mathrm{L}$ of whole blood suspension was carefully added to the bottom of all tubes and platelet activation-dependent monoclonal antibodies of PAC1, FITC and CD62 PE were added. Specificity of PAC1 binding is demonstrated by staining in the presence of RGDS peptide (a competitive inhibitor) as the negative control tube. Without vortex mixing, the tubes were gently mixed and incubated in the dark for 15 to 20 minutes at room temperature. Following the incubation period, $1 \mathrm{~mL}$ of cold $1 \%$ paraformaldehyde was added to each tube and they were finally stored at $2-8{ }^{\circ} \mathrm{C}$ in the dark for at least 2 hours. The percentage of activated platelets was counted by Flow Cytometer (BD FacsCanto).

The platelet and blood cell adhesion on the membrane surfaces was determined by incubating the samples at $37{ }^{\circ} \mathrm{C}$ with platelet rich plasma (PRP) and heparinized fresh human blood for 25 and 15 min, respectively. After incubation, the samples were gently washed to remove loosely bound platelets and blood cells, fixed with glutaraldehyde $(2.5 \%$ in $0.1 \mathrm{M}$ sodium cacodylate buffer, $\mathrm{pH}$ 7.2) for $30 \mathrm{~min}$ at $4{ }^{\circ} \mathrm{C}$, and rinsed three times with PBS buffer $(0.1 \mathrm{M}, \mathrm{pH}$ 7.4). The samples were then dehydrated in graded ethanol series $(30,50,70,90$, and $100 \%$, $500 \mathrm{~mL}$ each) for $10 \mathrm{~min}$ each and air dried. Finally, they were sputtered with gold and analyzed with SEM (FEIQuanta 250 FEG).

\subsection{Blood coagulation time}

Blood coagulation time was measured by APTT. The sample membrane $\left(1 \times 1 \mathrm{~cm}^{2}\right)$ was put in a glass tube,
$100 \mu \mathrm{l}$ of actin activated cephaloplastin reagent (Dade Behring Inc., USA) was added, and the tube was incubated at $37{ }^{\circ} \mathrm{C}$ for $1 \mathrm{~min}$. Then, $100 \mu \mathrm{l}$ of PPP solution was added to the sample solution at $37^{\circ} \mathrm{C}$, it was incubated for $30 \mathrm{~min}$, and finally $100 \mu \mathrm{l}$ of $0.025 \mathrm{M} \mathrm{CaCl}_{2}$ solution was added. The clotting time of the plasma solution was recorded at the first sign of fibrin formation [3].

To determine stability of immobilized HEP under typical hemodialysis conditions, blood coagulation time (APTT) was measured in the same manner, after the membranes were immersed into $10 \mathrm{~mL}$ of $0.05 \mathrm{M}$ phosphate buffer solution at $\mathrm{pH} 7.4$ and $37^{\circ} \mathrm{C}$. The solution was stirred thoroughly and the membrane samples were removed from the solution after $240 \mathrm{~min}$.

\subsection{Cell viability assay}

To determine toxic effects of the membranes, peripheral blood mononuclear cells (PBMCs) were isolated from the sample of healthy human blood by using ficol hypec gradient centrifugation. The membranes $(1.5 \times 1.5 \mathrm{~cm})$ were placed in 96 well-plate with $200 \mu$ PBMCs sample and maintained at $37{ }^{\circ} \mathrm{C}$ for $4 \mathrm{~h}$. The number of live and dead cells were determined with Flow cytometer (BD FacsCanto). For labeling live and dead cells; Thiazole Orange (TO) and Propidium Iodide (PI) were used, respectively.

\subsection{Permeation experiments}

Permeation experiments were carried out in a side by side diffusion cell (Permegear Membrane Transport Systems) using urea, vitamin B12 and lysozyme as model solutes. Samples were removed from each chamber at given time intervals and concentration of myoglobin and vitamin B12 were determined by directly measuring their natural absorbance at 409 and $360 \mathrm{~nm}$, respectively. The concentration of urea was determined by first adding an enzymatic reagent (BT Product, Turkey) and then reading the absorbance of this mixture at $340 \mathrm{~nm}$. The overall mass transfer coefficient which has contributions both from the bulk fluid and the membrane was evaluated from the solute concentration data [20]. The effective permeability of the solute was determined from the overall and individual mass transfer coefficients [20].

\subsection{Data analysis}

The data were analyzed with the statistical software Minitab 15 using Student's paired $t$ test. The probability $(P)$ values $P<0.05$ were considered to be statistically significant differences. The results were expressed as mean \pm standard error. 


\section{Results and discussion}

\subsection{Surface characterization of the membranes}

The first surface characteristic of the membranes investigated was their hydrophilicity since it plays an important role in thrombogenesis [21]. The hydrophilicity was determined through contact angle measurements and the results are shown in Fig. 1. It is seen that the hydrophilic character of the PSF membrane was remarkably improved by blending PSF with SPSF and depositing polyelectrolyte layers on the PSF-SPSF membrane as observed by a

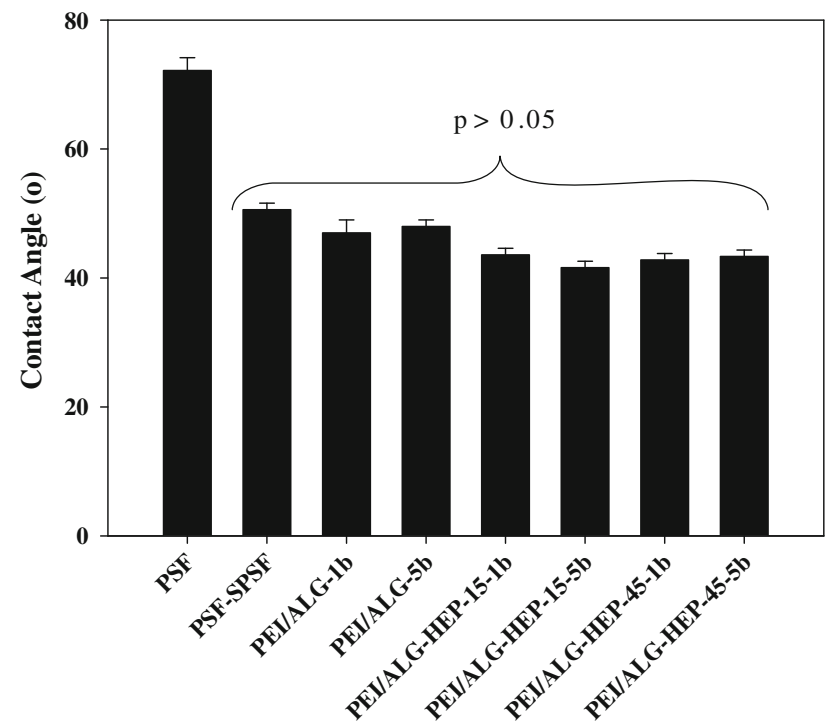

Fig. 1 Water contact angles of the unmodified and modified PSF membranes

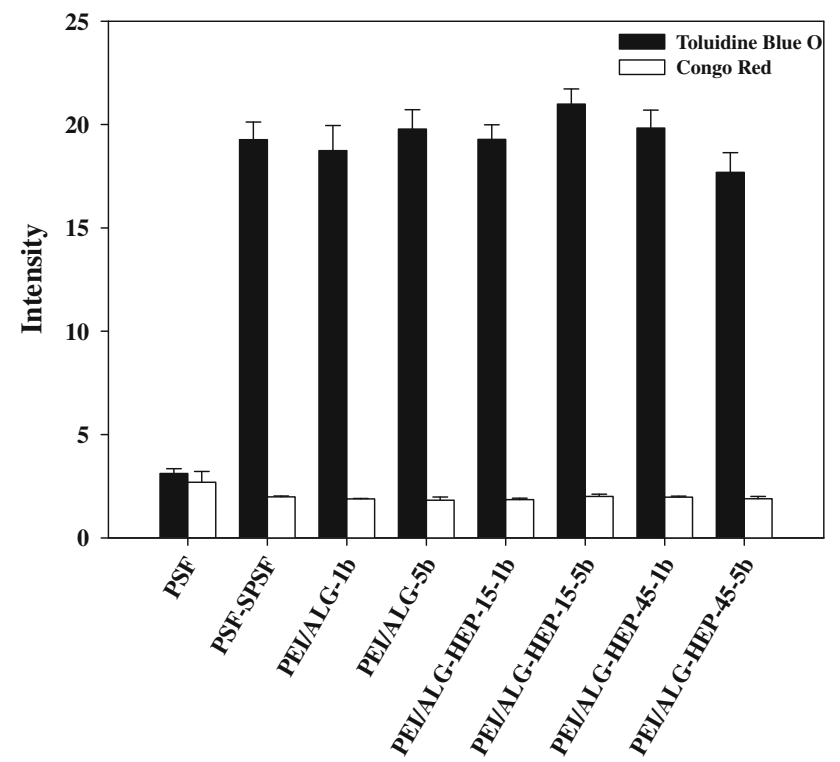

Fig. 2 Intensity of colours of Toluidine Blue $\mathrm{O}$ and Congo Red dyes adsorbed on the unmodified and modified PSF membranes decrease in the contact angle values. Increasing the number of polyelectrolyte layer or the HEP concentration in the ALG-HEP blend solution did not change the contact angles.

The surface charge of the membranes was determined by the staining technique. The results in Fig. 2 illustrate that all the PEI/ALG or PEI/ALG-HEP coated membranes were significantly stained with basic toluidine blue o dye. The intensity of blue colour compared to that of red colour was found much higher. This simply indicates that the net charges of the PSF-SPSF and all the polyelectrolyte deposited membranes are negative.

Figure 3a shows the FTIR spectra of ALG and ALGHEP in the form of the multilayer films. ALG layer consists of two distinct adsorption bands of the carboxylic acid functional groups; $v=1,565-1,542 \mathrm{~cm}^{-1}$ (asymmetric stretching band of $\mathrm{COO}^{-}$) and $v=1,710-1,700 \mathrm{~cm}^{-1}$ $(\mathrm{C}=\mathrm{O}$ stretching of $\mathrm{COOH})$. In the case of ALG-HEP layer, $\mathrm{S}-\mathrm{O}$ stretching modes of $\mathrm{SO}_{3}$ groups in HEP was also seen
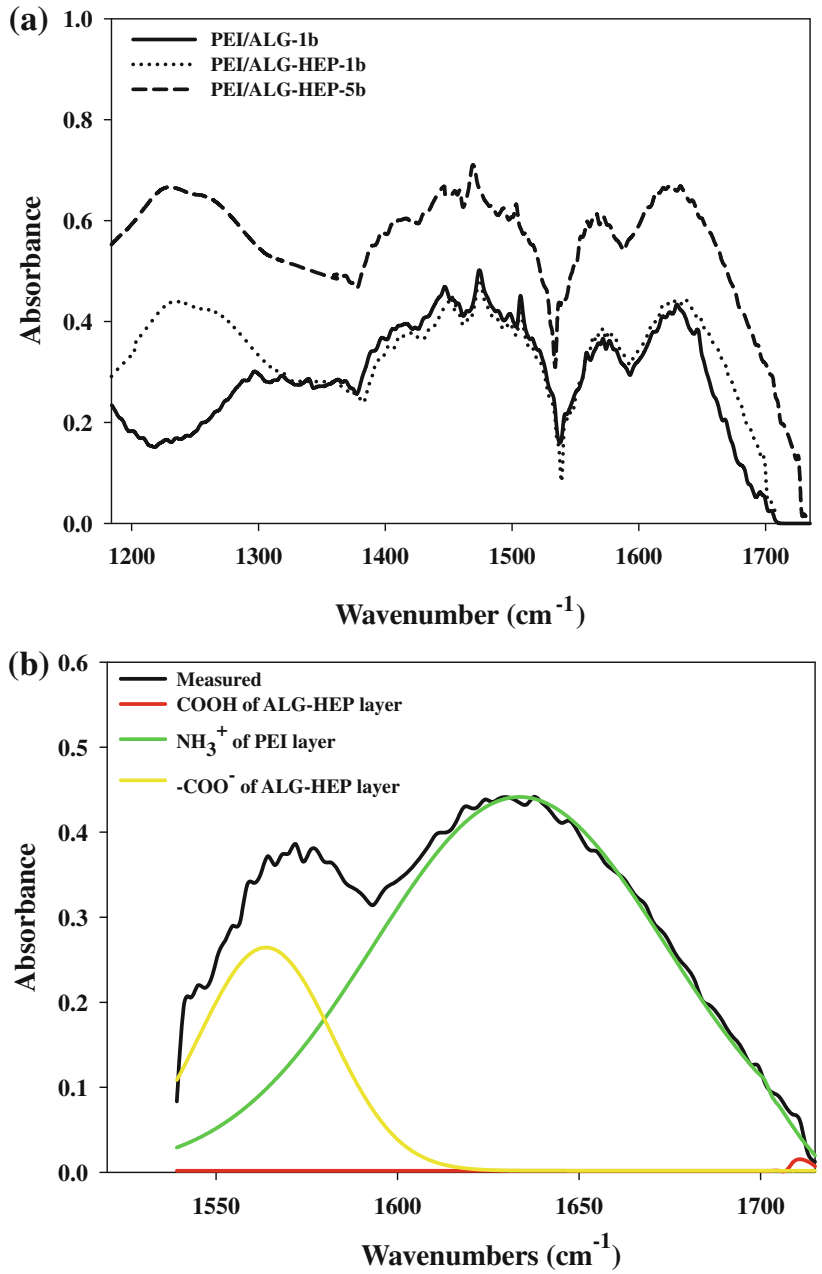

Fig. 3 Representative FTIR-ATR spectra of a PEI/ALG-HEP or PEI/ ALG multilayers on the ZnSe substrate and $\mathbf{b}$ an example of a peak fitting result for the 1 bilayer PEI/ALG-HEP multilayers 
centered at $1,230 \mathrm{~cm}^{-1}$. Asymmetric $\mathrm{NH}^{+}$bending band of PEI at $1,630 \mathrm{~cm}^{-1}$ overlaps with the adsorption bands of the carboxylic acid functional groups in ALG-HEP layer. To solve this problem, each band of ALG-HEP and PEI was deconvoluted by assuming a Gaussian distribution and using Microcal Origin software (Fig. 3b). The band intensity was estimated from the maximum peak height of each adsorption band. The degree of ionization of ALG-HEP layer in 1 and 5 bilayer multilayer formation was calculated from $\alpha=\left[\gamma_{\mathrm{COO}^{-}}\right] /\left[\gamma_{\mathrm{COO}^{-}}+\gamma_{\mathrm{COOH}}\right]$ assuming the same extinction coefficients for both bands. As can be seen from
Fig. 3b, almost all of the $\mathrm{COOH}$ groups were transformed into $\mathrm{COO}^{-}$form, hence, the degree of ionization was calculated as 0.99 and 0.97 for 1 and 5 bilayer formation, respectively. The degree of ionization of ALG and HEP in the solution has also a similar value $(0.99)$ which indicates that there is no change in the ionizable groups during adsorption of these polyelectrolytes. The presence of $\mathrm{S}-\mathrm{O}$ stretching modes of $\mathrm{SO}_{3}$ groups at around $1,230 \mathrm{~cm}^{-1}$, moreover, the increase of the signal intensity for the 5-bilayer coating compared to the 1-bilayer one shown in Fig. 3a are clear evidences of the multilayer film formation.
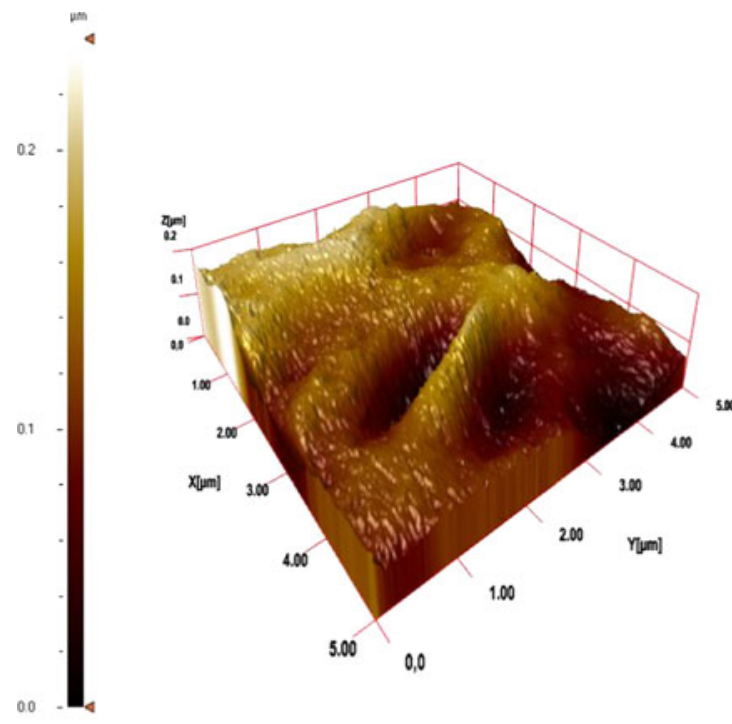

(a)

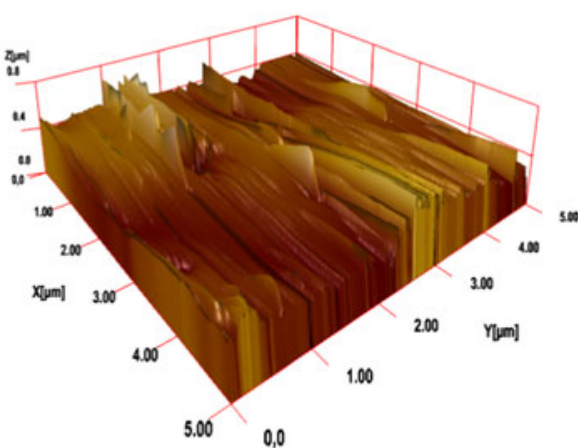

(b)

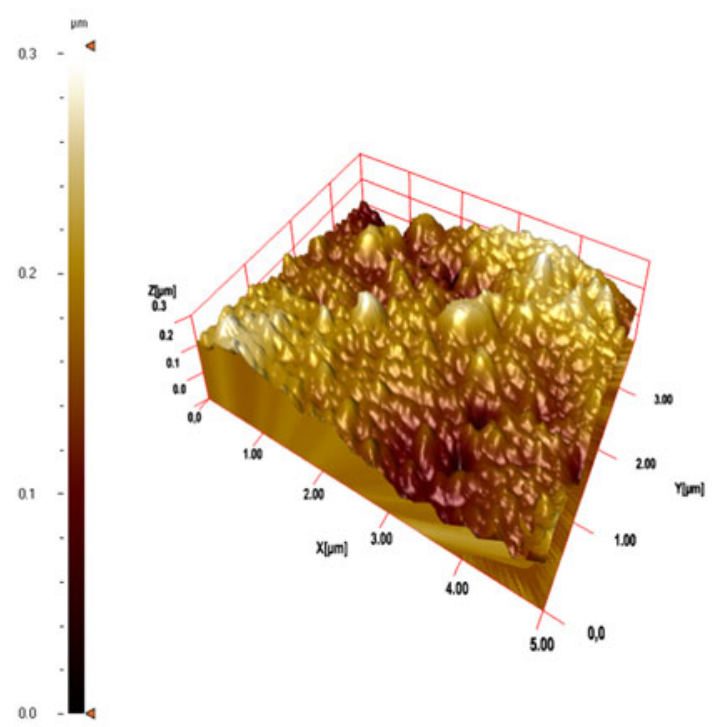

(c)

Fig. 4 AFM images of a PSF, b PSF-SPSF and c PEI/ALG-HEP-15-1b membranes 
The average surface roughness of the membranes was obtained from the analysis of AFM images shown in Fig. 4. The unmodified PSF membrane had the smoothest surface

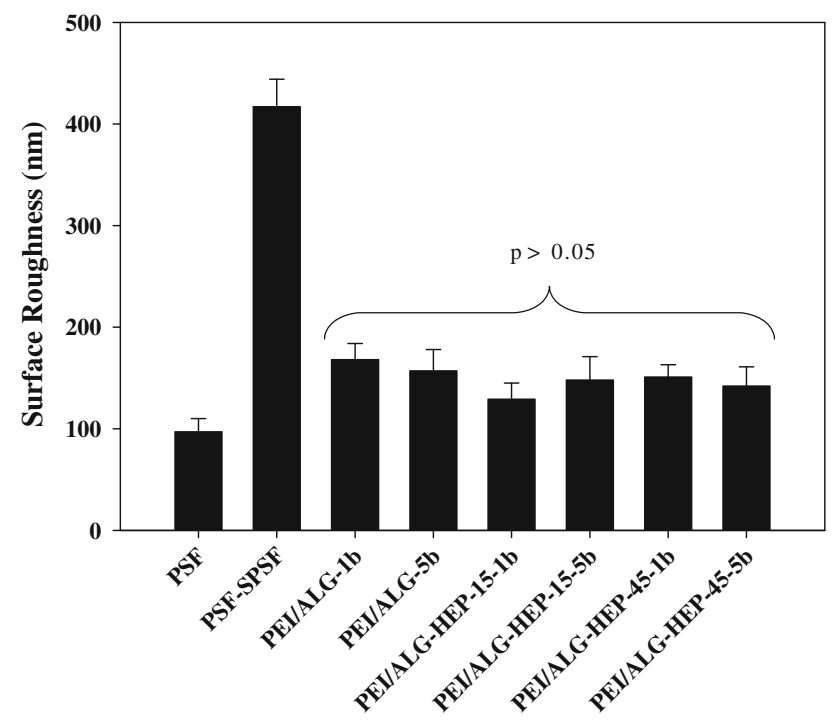

Fig. 5 Surface roughness of unmodified and modified membranes

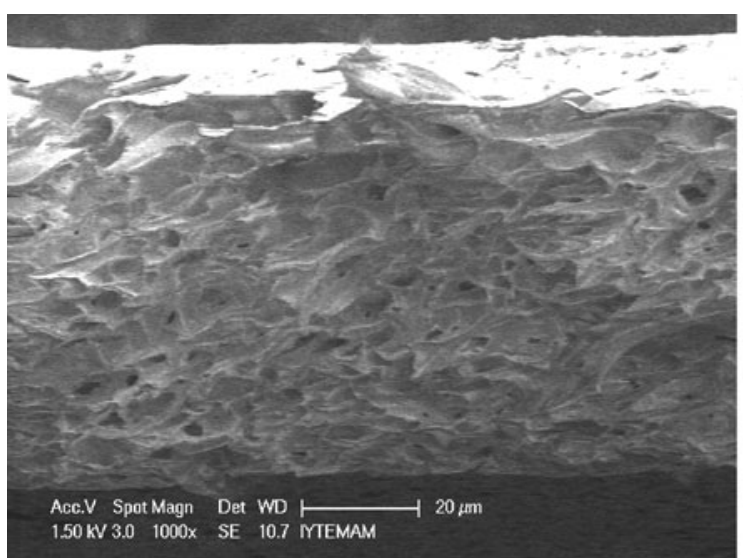

(a)

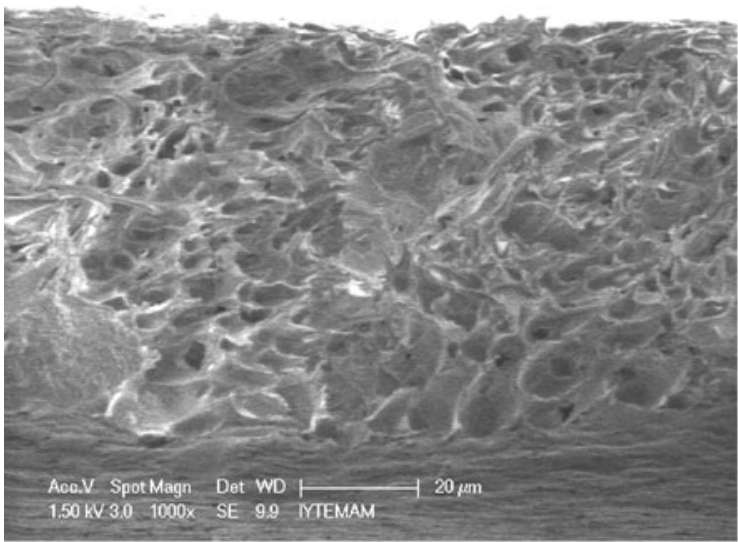

(c) while sulfonation significantly increased the surface roughness. On the other hand, the layer by layer deposition of PEI/ALG or PEI/ALG-HEP on the surface of PSF-SPSF improved the smoothness of the surface (Fig. 5). This can be attributed to the energy-minimization process taken place on the surface of the deposited film, where PEI undergoes deformation to minimize the surface area as a result of enhanced diffusional mobility of linear PEI chains.

The change in the bulk structure of the PSF membrane through blending with SPSF and polyelectrolyte deposition was observed with the SEM pictures. Figure 6 shows that native (PSF) and modified membranes have asymmetric structures. The PSF-SPSF membrane is more porous than the PSF membrane, however, these pores were blocked with polyelectrolytes, therefore, the bulk structures of the PSF and the 1- and 5-bilayer PEI/ALG-HEP coated membranes are similar.

\subsection{Protein adsorption capacity of the membranes}

Plasma protein adsorption on the membrane is the key phenomena during thrombogenic formation [22], therefore,

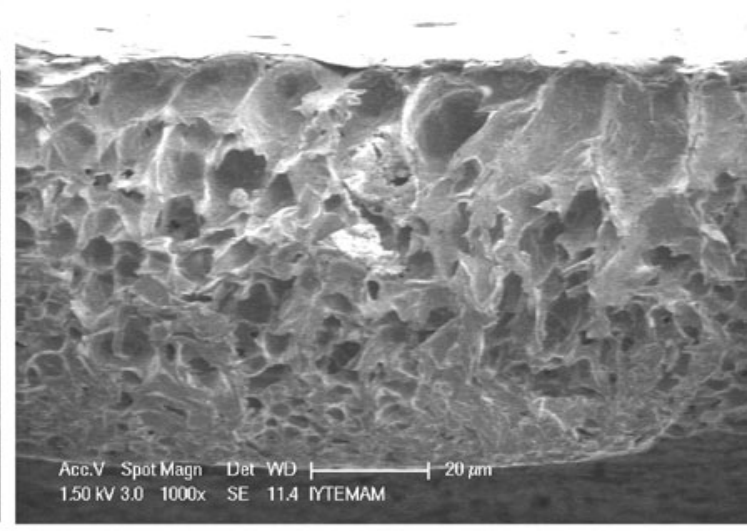

(b)

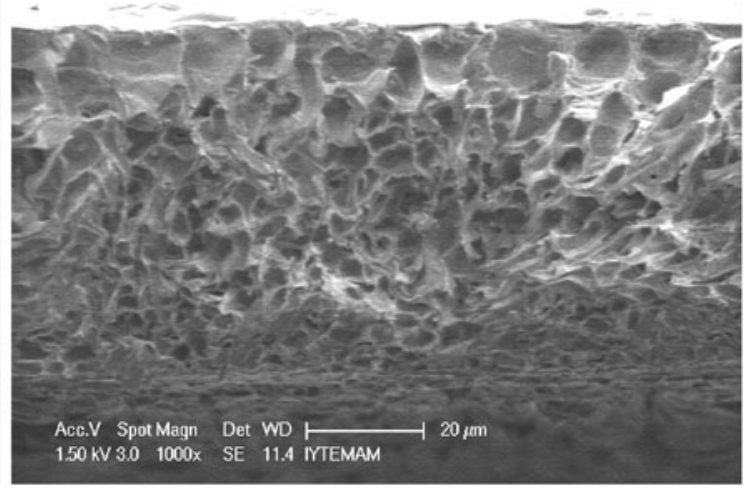

(d)

Fig. 6 Cross section SEM pictures of a PSF, b PSF-SPSF, c PEI/ALG-HEP-15-1b, d PEI/ALG-HEP-45-5b membranes. Magnification 1000× 


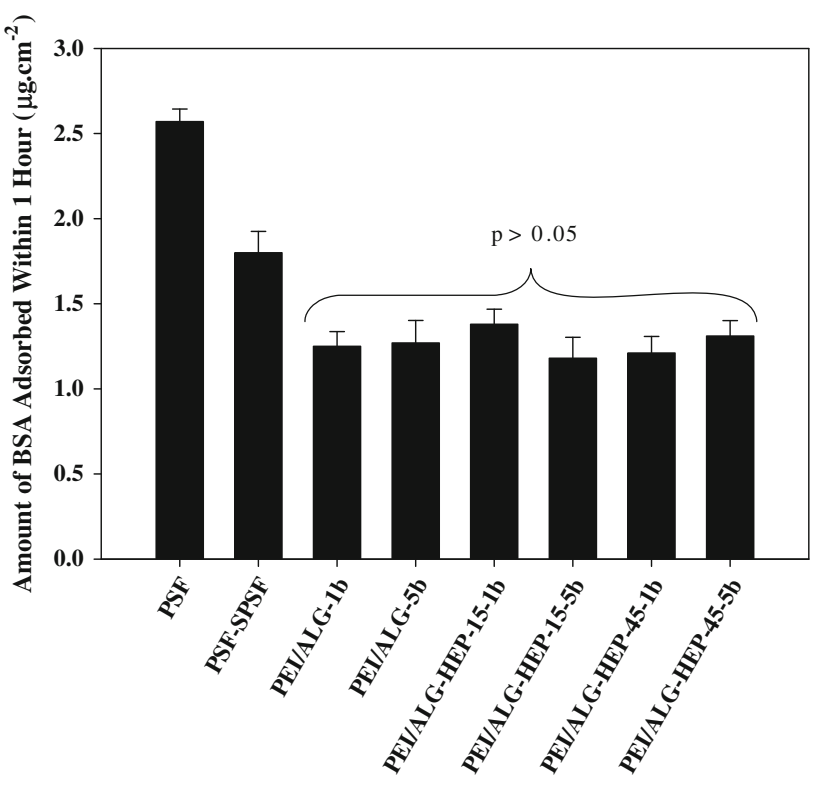

Fig. 7 Amount of BSA adsorbed onto the unmodified and modified PSF membranes

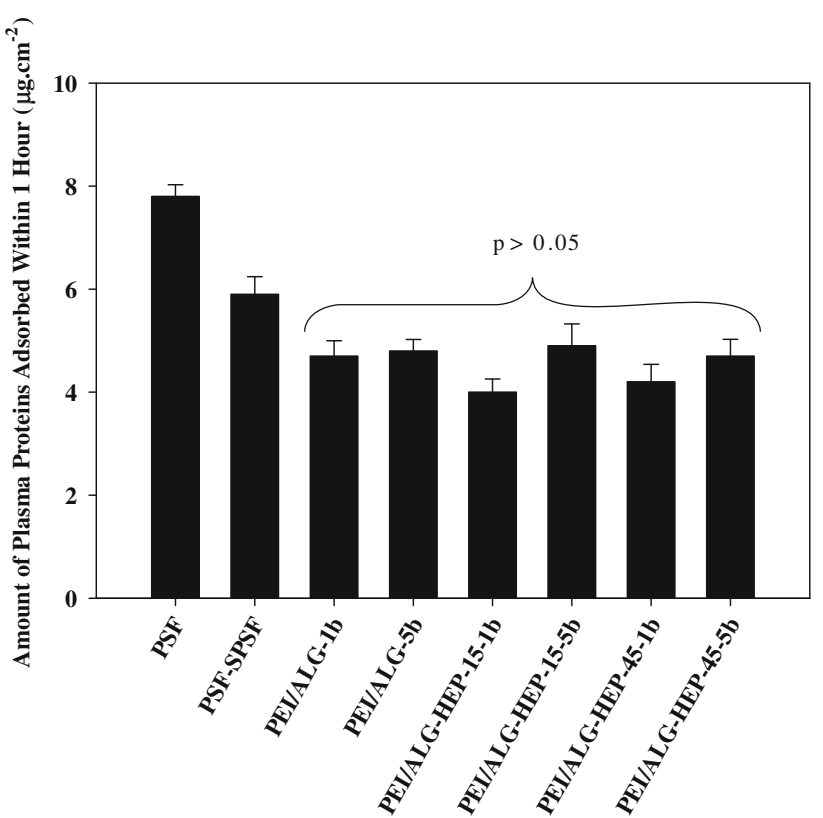

Fig. 8 Amount of blood plasma proteins adsorbed on the unmodified and modified PSF membranes

protein adsorption capacities of all the membranes were determined. The experiments were first performed with a negatively charged BSA, to represent most of the negatively charged proteins in blood. It is seen from Fig. 7 that the highest BSA adsorption occured on most hydrophobic PSF membrane. Blending PSF with SPSF and depositing polyelectrolytes on the PSF-SPSF blend membrane

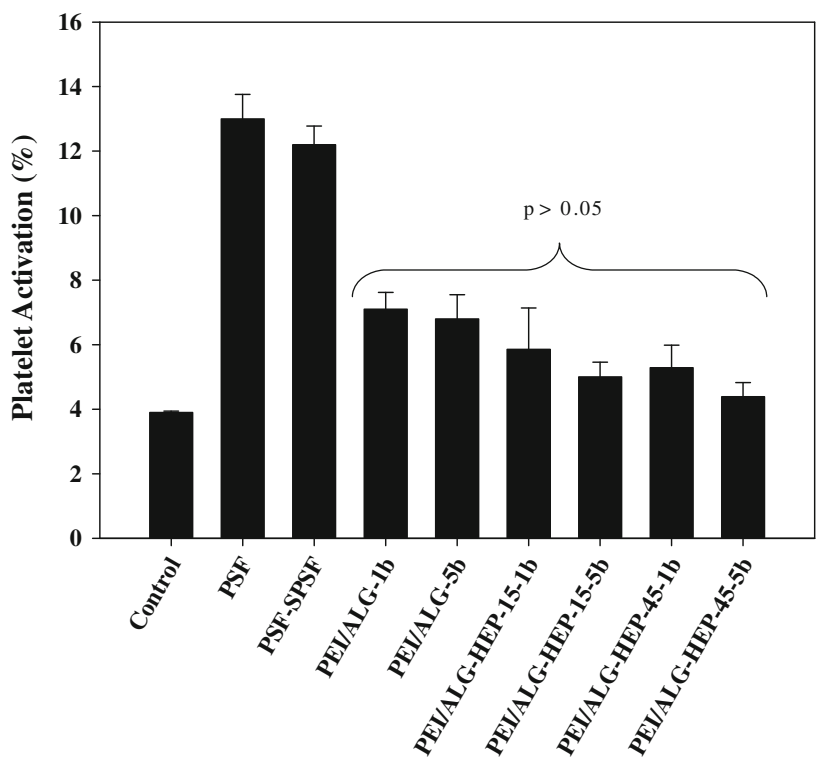

Fig. 9 Amount of platelet activation on the unmodified and modified PSF membranes

reduced protein adsorption by 30 and $51 \%$, respectively. Although the PSF membrane has the smoothest surface, the strong protein binding affinity of this membrane is due to hydrophobic groups on the surface while less protein binding to the blend and polyelectrolyte deposited membranes is related to their more hydrophilic character compared to the PSF membrane as shown in Fig. 1. In addition to hydrophobic interactions, electrostatic interactions are also effective on the protein adsorption. During protein adsorption experiments, BSA was negatively charged since its isoelectric point, $\mathrm{pI}$ : 4.9 , is lower than the $\mathrm{pH}$ of the solution adjusted to physiological $\mathrm{pH}$ 7.4. The PSF membrane has no charged group on the surface, on the other hand, the PSF-SPSF and the 1- and 5-bilayer PEI/ALG and PEI/ALG-HEP coated membranes carry negatively charged $-\mathrm{OSO}_{3}{ }^{-}$and $-\mathrm{COO}^{-}$groups that can repel BSA due to electrostatic interactions. The PEI/ALG or PEI/ ALG-HEP coated membranes adsorb less protein than the PSF-SPSF membrane since their surfaces are much more smooth. Not only BSA but also blood plasma proteins adsorbed on the membranes were determined and the results are shown in Fig. 8. The decrease in the adsorption of plasma proteins on the membranes due to PEI/ALG or PEI/ALG-HEP immobilization $(\sim 42 \%)$ is not as high as in the case of BSA adsorption $(\sim 51 \%)$. This is expected since human plasma proteins are a mixture of approximately 200 kinds with different charge, hydrophobicity and structure, consequently, their adsorption mechanism is quite complicated. The results in Figs. 7 and 8 show that all the polyelectrolyte deposited membranes have similar BSA and plasma protein adsorption capacities $(P>0.05)$. This 


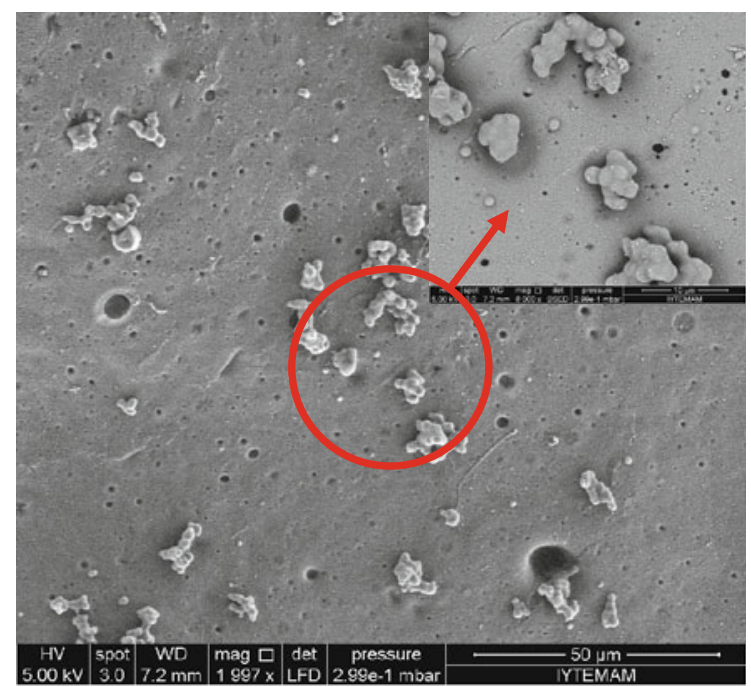

(a)

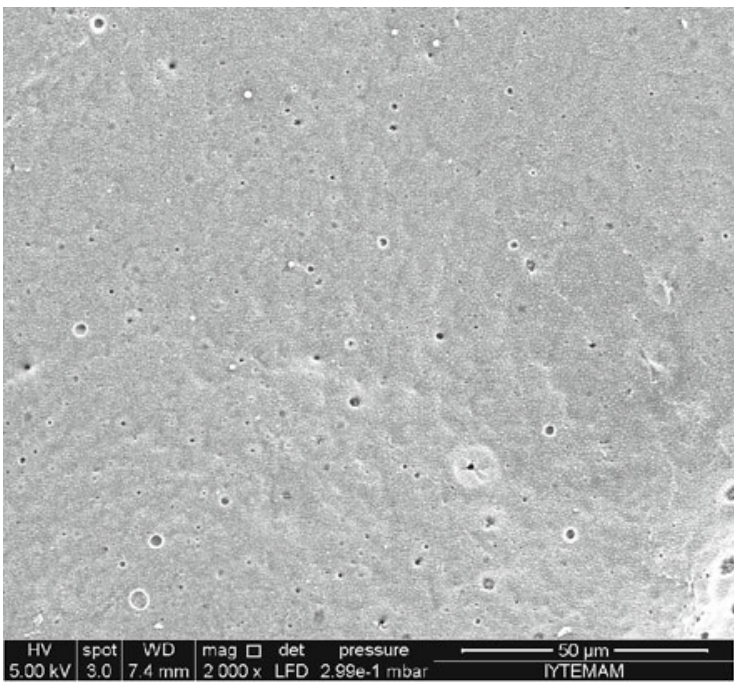

(c)

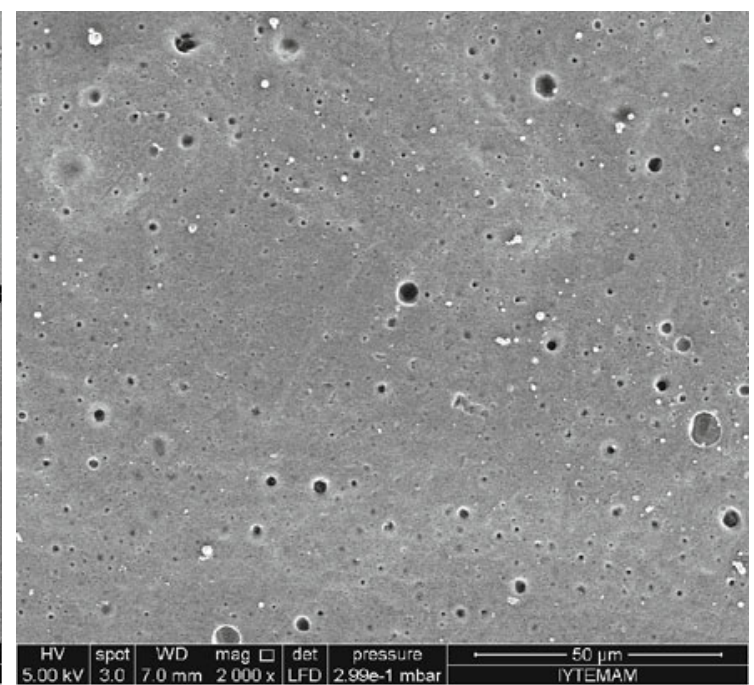

(b)

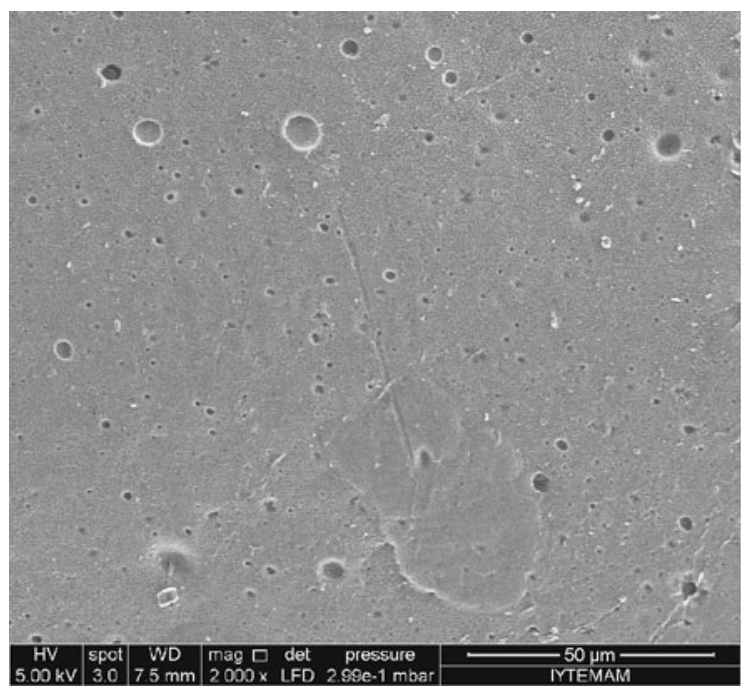

(d)

Fig. 10 The SEM pictures of unmodified and modified PSF membranes after incubating with PRP for 25 min a PSF, b PSF-SPSF, $\mathbf{c}$ PEI/ALGHEP-15-1b, d PEI/ALG-HEP-45-5b, magnification 2000×

could be attributed to similar hydrophilicity, surface charge and surface roughnesses of these membranes as shown in Figs. 1, 2 and 5, respectively.

\subsection{Platelet and blood cell activation on the membranes}

Platelets play a crucial role in the coagulation by secreting or releasing prothrombotic factors, therefore, platelet activation on different membranes was determined. Figure 9 shows that the highest platelet activation occurred on the PSF and PSF-SPSF membranes, on the other hand, polyelectrolyte deposition remarkably decreased the activation $(P<0.05)$. All the PEI/ALG and PEI/ALG-HEP coated membranes did not show significantly different activation
$(P>0.05)$. The reduction of platelet activation on the polyelectrolyte deposited membranes can be attributed to decreased plasma protein adsorption capacities of these membranes. Among various proteins in blood, adsorption and conformational change of fibrinogen is known to regulate the adhesion and activation of platelets [23]. Better blood compatibility of the heparin immobilized membranes (PEI/ALG-HEP) may due to maintenance of the native conformation of adsorbed proteins [24].

To identify the adherent platelets on the membranes, scanning electron microscope pictures were also used. When activation starts, multiple prothrombotic factors are released and the platelets change from disc to varying degrees of dendritic shape. It is seen from Fig. 10 that more 


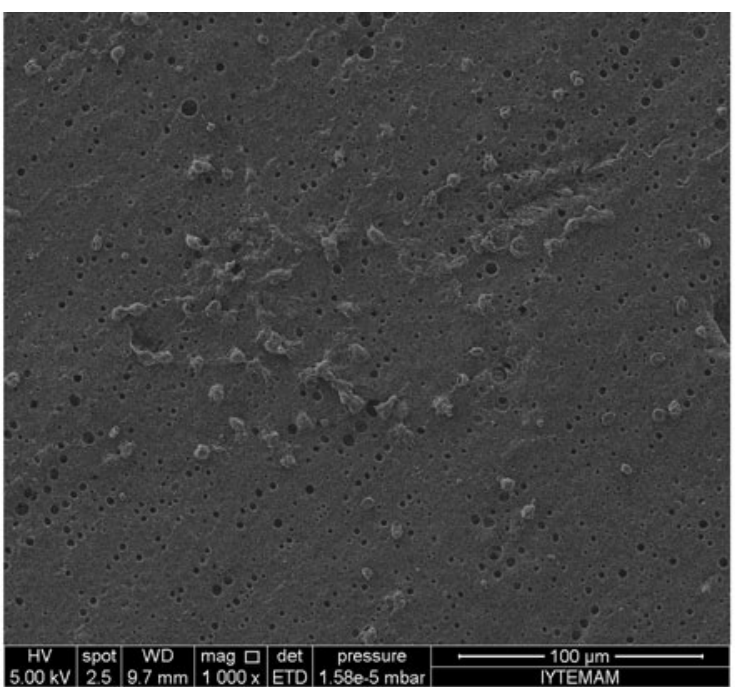

(a)

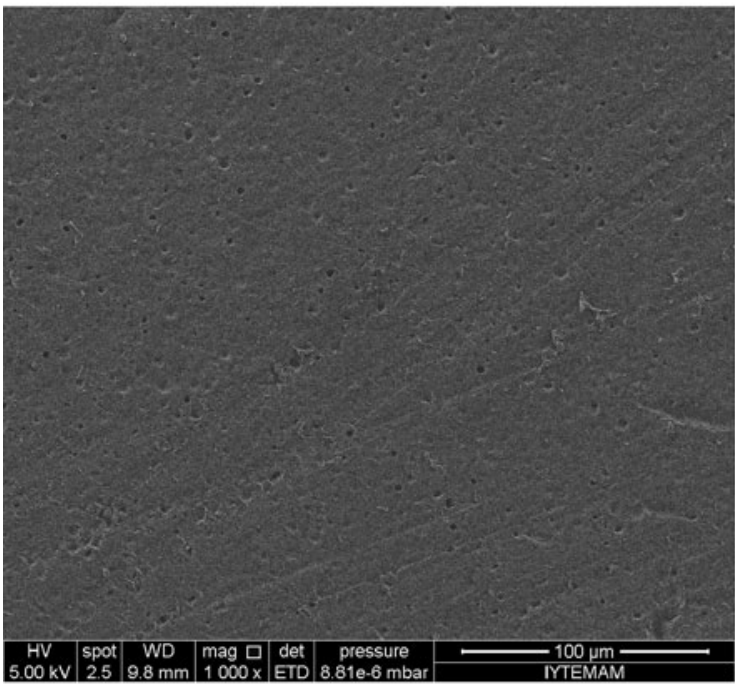

(c)

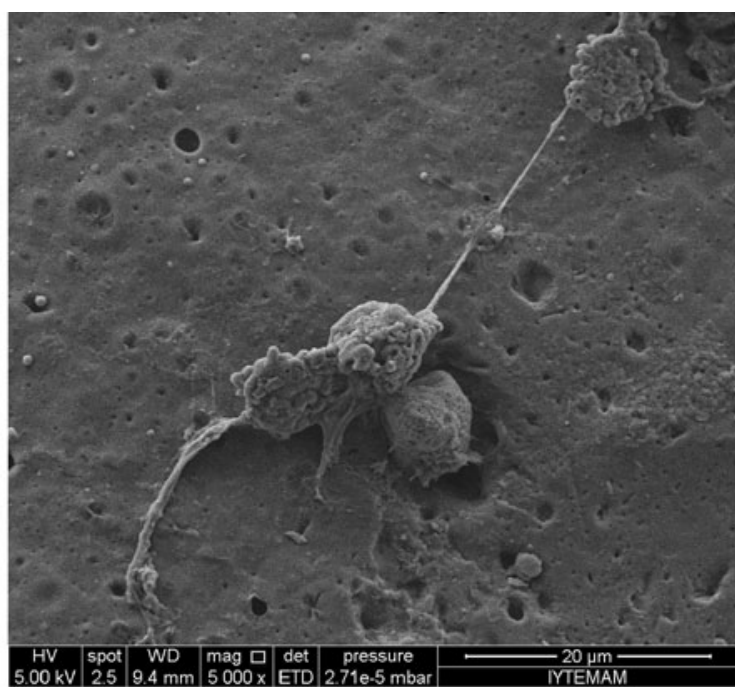

(b)

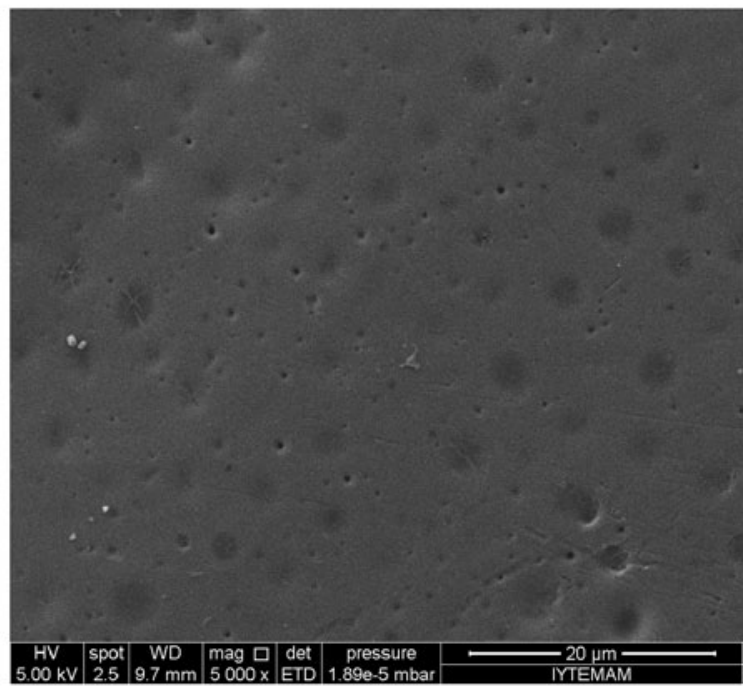

(d)

Fig. 11 The SEM pictures of a-b PSF-SPSF and c-d PEI/ALG-HEP-15-1b membranes after incubating in whole blood for 15 min. Magnification a-c $1000 \times$ and (b-d) $5000 \times$

platelets adhered on the PSF and PSF-SPSF membranes than the PEI/ALG-HEP coated membranes and they had mainly dendritic shapes indicating the beginning of the platelet activation.

Figure $11 \mathrm{a}, \mathrm{b}$ show that not only platelets but also mononuclear cells attached to the uncoated PSF-SPSF surface and changed their morphology which is a clear sign of activation. In contrast, fewer adhered cells were detected on the PEI/ALG-HEP coated membranes and no signs of morphology change was observed (Fig. 11c, d) primarily due to much more smooth surfaces of these membranes and presence of an anticoagulant agent which is in contact with blood cells.

\subsection{Activated partial thromboplastin time (APTT)}

The anticoagulant property of the heparin immobilized membranes was determined by means of APTT. The unmodified PSF, PSF-SPSF and PEI/ALG deposited membranes were used as reference samples. The APTT values for the samples are listed in Table 2. All heparin immobilized membranes displayed significantly longer APTT values than other membranes and the control. In the absence of heparin, improvement in the APTT values of the PEI/ALG coated membranes compared with those of PSF and PSF-SPSF membranes is due to their decreased protein adsorption capacities and platelet activation. 
Table 2 APTT values of the unmodified and modified PSF membranes

\begin{tabular}{lcc}
\hline Membrane Type & \multicolumn{2}{l}{ APTT $(\mathrm{sec})$} \\
\cline { 2 - 3 } & Before treatment & After treatment \\
\hline Control & $35 \pm 3$ & $35 \pm 3$ \\
PSF-SPSF & $37 \pm 2$ & $35 \pm 5$ \\
PEI/ALG-1b & $63 \pm 5$ & $59 \pm 3$ \\
PEI/ALG-5b & $57 \pm 7$ & $52 \pm 9$ \\
PEI/ALG-HEP-15-1b & $195 \pm 43$ & $142 \pm 43$ \\
PEI/ALG-HEP-15-5b & $195 \pm 43$ & $115 \pm 40$ \\
PEI/ALG-HEP-45-1b & $247 \pm 35$ & $195 \pm 43$ \\
PEI/ALG-HEP-45-5b & $221 \pm 40$ & $195 \pm 43$ \\
PEI/ALG-HEP-100-1b & $195 \pm 43$ & $169 \pm 44$ \\
PEI/ALG-HEP-100-5b & $221 \pm 40$ & $142 \pm 43$ \\
\hline
\end{tabular}

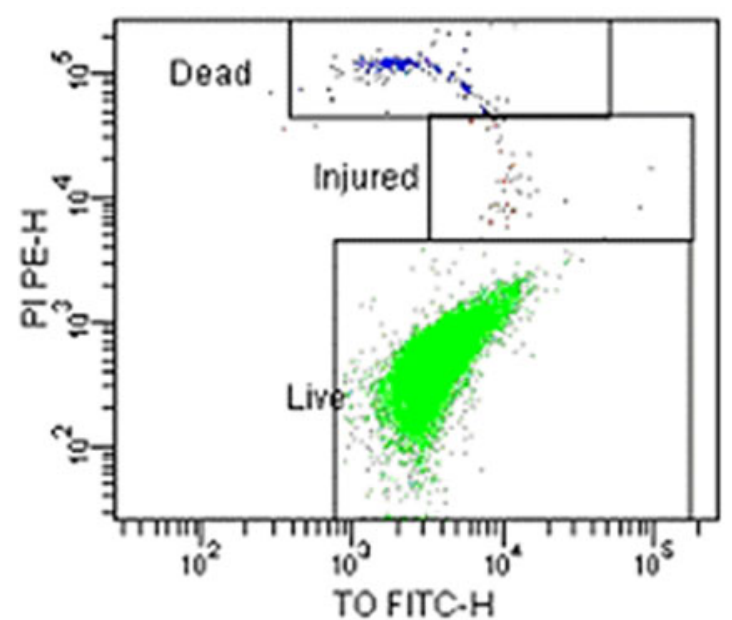

(a)

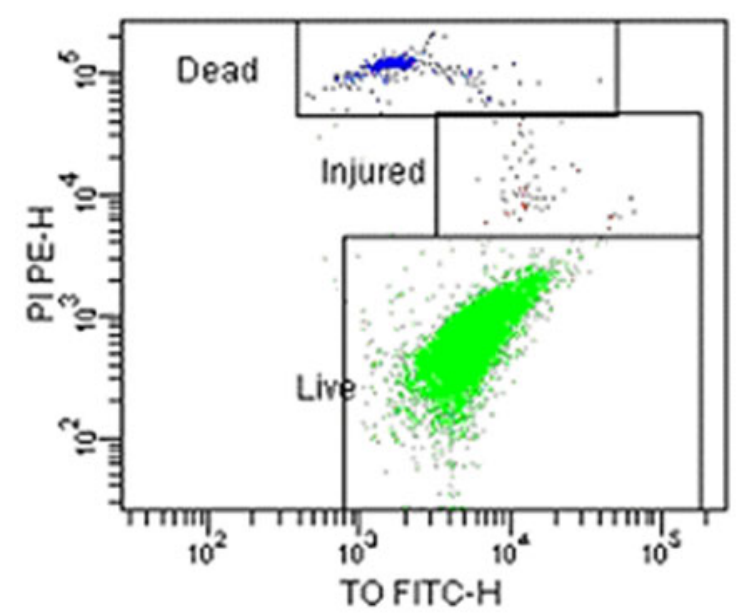

(c)
Increasing the number of polyelectrolyte coated layers did not change the blood coagulation time $(P>0.05)$ since protein adsorption capacities of these membranes were similar and heparin mixed with ALG was coated only on the outermost layer of the assembly. In addition, no significant improvement in the APTT values was observed by increasing the initial concentration of heparin in the depositing solution first from 15 to $45 \%$ and further to $100 \%(P>0.05)$. This simply proves that diluting HEP with ALG does not cause a decrease in its biological activity. When HEP is blended with ALG, the surface of PEI is partly covered by long chained ALG, hence, most of the active sites of heparin, $-\mathrm{OSO}_{3}{ }^{-}$, which forms an ionic bond with the positively charged $\mathrm{NH}_{2}$ groups in PEI can become free, hence, its biological activity is preserved. The proposed strategy can be an economical alternative for the modification of hemodialysis membranes since HEP is an

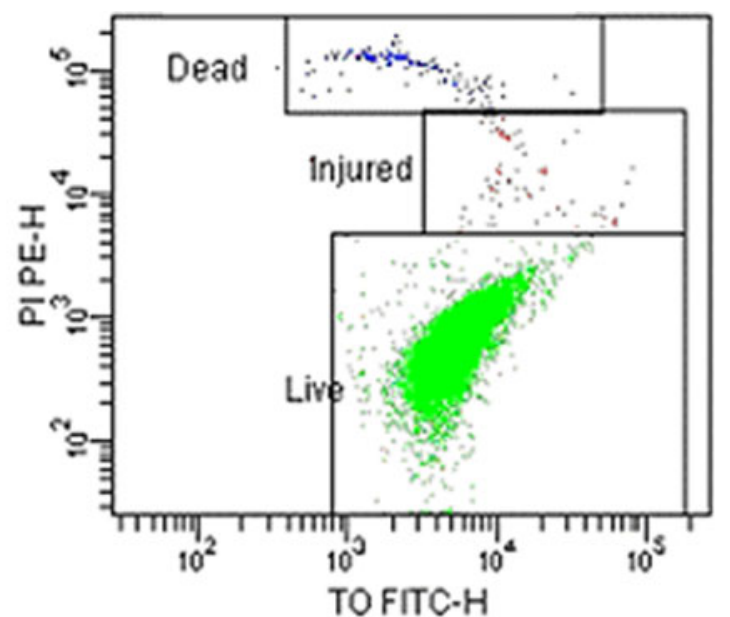

(b)

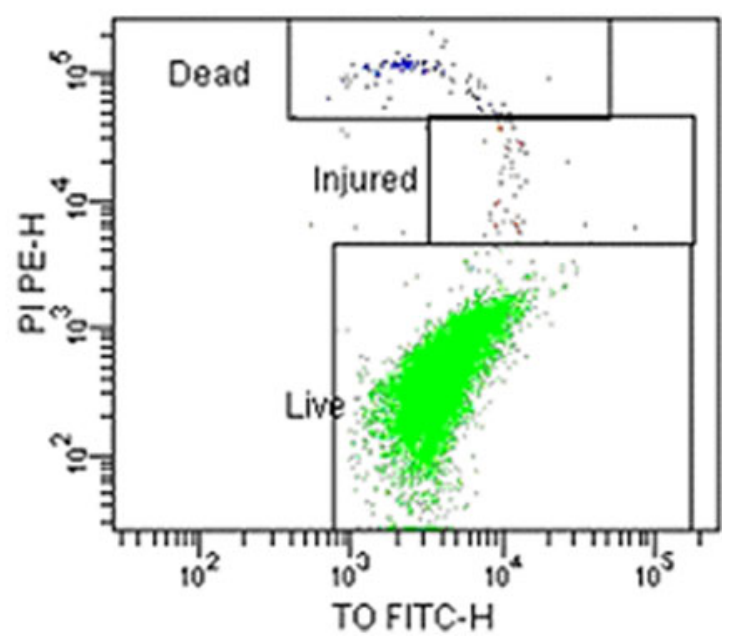

(d)

Fig. 12 Live and dead cells labeled with TO and PI after incubating PMBCs with a control, b PSF, c PSF-SPSF and d PEI/ALG-HEP-15-1b membranes 
Table $3 \%$ of live cells after incubating PMBCs with the unmodified and modified PSF membranes for $4 \mathrm{~h}$

\begin{tabular}{ll}
\hline Membrane type & Live cell $\%$ \\
\hline Control & $99.3 \pm 0.5$ \\
PSF-SPSF & $99.6 \pm 0.3$ \\
PEI/ALG-1b & $98.8 \pm 0.2$ \\
PEI/ALG-5b & $99.8 \pm 0.7$ \\
PEI/ALG-HEP-15-1b & $98.1 \pm 0.3$ \\
PEI/ALG-HEP-15-5b & $98.7 \pm 0.5$ \\
PEI/ALG-HEP-45-1b & $97.9 \pm 0.9$ \\
PEI/ALG-HEP-45-5b & $97.6 \pm 1.1$ \\
\hline
\end{tabular}

expensive compound compared to ALG. In previous studies, the LBL deposition of HEP with different polyelectrolytes such as chitosan, collagen, dextrin sulfate and albumin on different blood-contacting surfaces has been carried out [18, 25-29]. In these studies, HEP was used alone not only in the last layer of the assembly but also in each alternating layer to provide charge reversal of the polycation layer. Consequently, it is obvious that amount of HEP used in such assemblies is more than that required in the assembly proposed in this study.

The APTT values for the membranes after stored in $\mathrm{pH}$ 7.4 PBS at $37{ }^{\circ} \mathrm{C}$ for a period of $4 \mathrm{~h}$ were not found significantly different from those for the freshly prepared membranes $(P>0.05)$. This result suggests that ionic bonding of heparin to the surface is sufficiently strong and most of its anticoagulant activity is stable under typical hemodialysis conditions.

\subsection{Cytotoxicities of the membranes}

Cytotoxicities of the unmodified and modified PSF membranes were examined with peripheral blood mononuclear cells isolated from the sample of healthy human blood. Figure 12 shows live and dead cells labeled with TO and PI, respectively and Table 3 lists the percentage of live cells. The results demonstrated that toxic effects of all the membranes on the PMBCs are similar $(P>0.05)$ and proposed modification technique does not cause a negative effect on the nontoxic property of PSF.

\subsection{Transport properties of the membranes}

The results of permeation experiments showed that the differences in transport rates of all solutes through bare PSF membrane, PSF-SPSF blend membrane and PEI/ALGHEP coated membranes are statistically insignificant $(P>0.05)$ (Fig. 13). This was an expected result since the

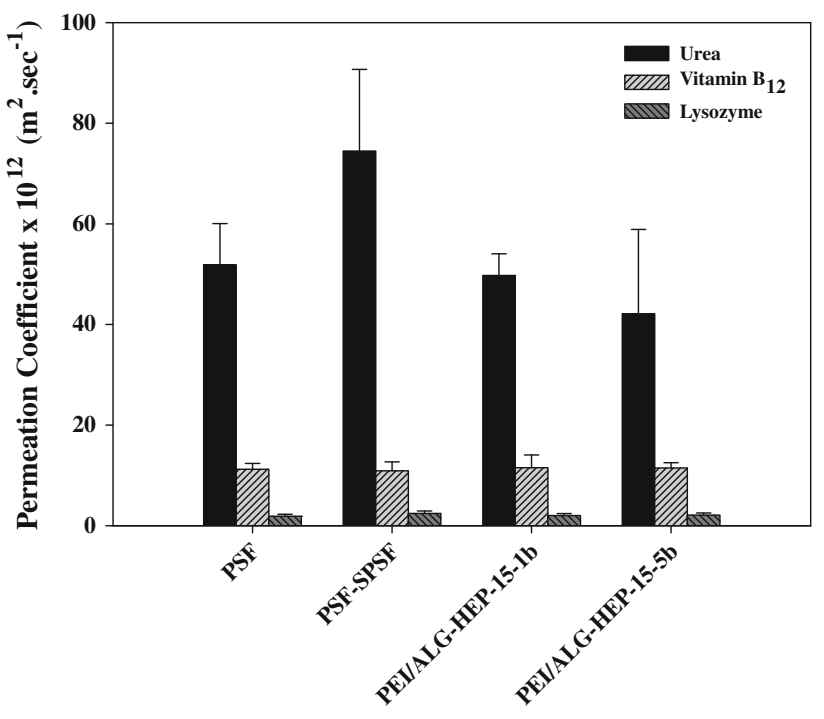

Fig. 13 The permeation coefficient of urea, vitamin B12 and lysozyme through the unmodified and modified PSF membranes

Table 4 Mechanical properties of the unmodified and modified PSF membranes

\begin{tabular}{lll}
\hline Membrane type & $\begin{array}{l}\text { Maximum tensile } \\
\text { stress }(\mathrm{MPa})\end{array}$ & $\begin{array}{l}\text { Young modulus } \\
(\mathrm{MPa})\end{array}$ \\
\hline PSF & $2.78 \pm 0.22$ & $39.82 \pm 5.97$ \\
PSF-SPSF & $2.25 \pm 0.18$ & $50.25 \pm 7.54$ \\
PEI/ALG-HEP-15-1b & $2.04 \pm 0.16$ & $43.17 \pm 6.48$ \\
PEI/ALG-HEP-15-5b & $2.96 \pm 0.24$ & $45.71 \pm 6.86$ \\
\hline
\end{tabular}

bulk structure of all the membranes were similar as shown in Fig. 6. Moreover, additional mass transfer resistance due to polyelectrolyte deposition is rather small since the increase in the total thickness is negligible. The clearing performance of the unmodified and modified membranes for lysozyme and vitamin B12 are comparable with those of the industrial hemodialysis membranes AN69 $(1.5 \times$ $10^{-12} \mathrm{~m}^{2} \mathrm{~s}^{-1}$ for $\mathrm{MW}=15,000 ; 4.0 \times 10^{-11} \mathrm{~m}^{2} \mathrm{~s}^{-1}$ for MW = 1,700) and Cuprophan $\left(1.0 \times 10^{-13} \mathrm{~m}^{2} \mathrm{~s}^{-1} \mathrm{MW}=\right.$ 15,$\left.000 ; 1.5 \times 10^{-11} \mathrm{~m}^{2} \mathrm{~s}^{-1} \mathrm{MW}=1,700\right)$, reported by Langsdorf et al. [20].

\subsection{Mechanical properties of the membranes}

Mechanical properties of the membranes were evaluated in terms of maximum tensile strength and Young's modulus values and the results are listed in Table 4. As expected, blending PSF with SPSF caused slight decrease in maximum tensile strength of the PSF membrane. While deposition of 1 bilayer polyelectrolyte on the PSF-SPSF membrane does not significantly change the mechanical 
properties $(P>0.05)$, the maximum tensile strength of the 5 bilayer polyelectrolyte coated membrane (PEI/ALGHEP-15-5b) is higher than both the PSF-SPSF and the 1 bilayer polyelectrolyte coated membrane (PEI/ALG-HEP15-1b). This can be attributed to elimination of defects on the surface of the membrane after 5 bilayer coating.

\section{Conclusion}

In the present work, it was aimed to improve the blood compatibility of PSF based hemodialysis membranes through heparin immobilization with LBL technique. In particular, the feasibility of using a blend of HEP and ALG in the outermost layer of the LBL assembly instead of utilizing HEP alone as polyanion in each alternating layer was tested. The APTT results have shown that diluting HEP with ALG does not cause a decrease in its biological activity, moreover, most of its anticoagulant activity is stable under typical hemodialysis conditions. It is sufficient to immobilize the HEP only in the terminating layer of the assembly for providing sufficient anticoagulant activity to the membranes. Polyelectrolyte deposition reduced the protein adsorption and the platelet activation on the PSFSPSF blend membranes. The PEI/ALG and PEI/ALG-HEP coated membranes did not show significantly different activation. While improving the blood compatibility of the PSF membranes, their desired properties such as nontoxicity and high permeation rates for toxic compounds were protected when the LBL assembly was formed on these membranes. The use of a blend of HEP and ALG proposed in this study can be an economical alternative for the modification of hemodialysis membranes since HEP is an expensive compound. Cost-effective modification of the hemodialysis membranes is critical since their reuse is forbidden in most countries. The blend approach can be extended to other expensive and highly functional biomolecules to immobilize on different blood-contacting devices.

Acknowledgments We gratefully acknowledge Izmir Institute of Technology, Biotechnology and Bioengineering Research and Application Center and Material Research Center to provide facilities for performing the in vitro blood compatibility tests and SEM analysis. We also acknowledge Metin UZ for AFM analysis.

\section{References}

1. Cheung AK, Parker CJ, Janatova J, Brynda E. Modulation of complement activation on hemodialysis membranes by immobilized heparin. J Am Soc Nephrol. 1992;2:1328-37.

2. Baumann H, Kokott A. Surface modification of the polymers present in a polysulfone hollow fiber hemodialyser by covalent binding of heparin or endothelial cell surface heparan sulfate:
Flow characteristics and platelet adhesion. J Biomater Sci Polym Ed. 2000;11:245-72.

3. Yang MC, Lin WC. Surface modification and blood compatibility of polyacrylonitrile membrane with immobilized chitosan-heparin conjugate. J Polym Res. 2002;9:201-6.

4. Yang MC, Lin WC. Protein adsorption and platelet adhesion of polysulfone membrane immobilized with chitosan and heparin conjugate. Polym Adv Technol. 2003;14:103-13.

5. Lin WC, Liu TY, Yang MC. Hemocompatibility of polyacrylonitrile dialysis membrane immobilized with chitosan and heparin conjugate. Biomaterials. 2004;25:1947-57.

6. Zhu LP, Yu JZ, Xu YY, Xi ZY, Zhu BK. Surface modification of PVDF porous membranes via poly(DOPA) coating and heparin immobilization. Collids Surf B Biointerfaces. 2009;69:152-5.

7. Jiang JH, Zhu LP, Li XL, Xu YY, Zhu BK. Surface modification of PE porous membranes based on the strong adhesion of polydopamine and covalent immobilization of heparin. J Memb Sci. 2010;364:194-202.

8. Huang XJ, Guduru D, Xu ZK, Vienken J, Groth T. Immobilization of heparin on polysulfone surface for selective adsorption of low-density lipoprotein (LDL). Acta Biomater. 2010;6:1099-106.

9. Huang XJ, Guduru D, Xu ZK, Vienken J, Groth T. Blood compatibility and permeability of heparin-modified polysulfone as potential membrane for simultaneous hemodialysis and LDL removal. Macromol Biosci. 2011;11:131-40.

10. Lavaud S, Canivet E, Wuillai A, Maheut H, Randoux C, Bonnet JM, Renaux JL, Chanard J. Optimal anticoagulation strategy in hemodialysis with heparin-coated polyacrylonitrile membrane. Nephrol Dial Transplant. 2003;18:2097-104.

11. Lee KB, Kim B, Lee YH, Yoon SJ, Kang WH, Huh W, Kim DJ, Oh HY. KimYG. Hemodialysis using heparin-bound Hemophan in patients at risk of bleeding. Nephron Clin Pract. 2004;97:5-10.

12. Chanard J, Lavaud S, Paris B, Toure F, Rieu P, Renaux JL, Thomas M. Assessment of heparin binding to the AN69 ST hemodialysis membrane: I. Preclinical studies. ASAIO J. 2005;51:342-7.

13. Lavaud S, Paris B, Maheut H, Randoux C, Renaux JL, Rieu P, Chanard J. Assessment of the heparin-binding AN69 ST hemodialysis membrane: II. Clinical studies without heparin administration. ASAIO J. 2005;51:348-51.

14. Chanard J, Lavaud S, Maheut H, Kazes I, Vitry F, Rieu P. The clinical evaluation of low-dose heparin in haemodialysis: a prospective study using the heparin-coated AN69 ST membrane. Nephrol Dial Transpl. 2008;23:2003-9.

15. Morena M, Jaussent I, Chalabi L, Bergnoux AS, Dupuy AM, Badiou S, Rakic C, Thomas M, Canoud B, Cristol JP. Biocompatibility of heparin-grafted hemodialysis membranes: impact on monocyte chemoattractant protein-1 circulating level and oxidative status. Hemodial Int. 2010;14:403-10.

16. Sagedal S, Witczak BJ, Osnes K, Hartmann A, Os I, Eikvar L, Klingenberg O, Brosstad F. A Heparin-coated dialysis filter (AN69 ST) does not reduce clotting during hemodialysis when compared to a conventional polysulfone filter $(\mathrm{F} \times 8)$. Blood Purif. 2011;32:151-5.

17. Quinn JF, Johnston APR, Such GK, Zelikin AN, Caruso F. Next generation, sequentially assembled ultrathin films: beyond electrostatics. Chem Soc Rev. 2007;36:707-18.

18. Sperling C, Houska M, Brynda E, Streller U, Werner C. In vitro hemocompatibility of albumin-heparin multilayer coatings on polyethersulfone prepared by the layer-bilayer technique. J Biomed Mater Res A. 2006;76A:681-9.

19. Blanco JF, Nguyen QT, Scaetzel P. Sulfonation of polysulfones: Suitability of the sulfonated materials for asymmetric membrane preparation. J Appl Polym Sci. 2002;84:2461-73.

20. Langsdorf LJ, Zydney AL. Diffusive and convective solute transport through hemodialysis membranes: a hydrodynamic analysis. J Biomed Mater Res. 1994;28:573-82. 
21. Spijker HT, Bos R, Busscher HJ, van Kooten TG, van Oeveren W. Platelet adhesion and activation on a shielded plasma gradient prepared on polyethylene. Biomaterials. 2002;23:757-66.

22. Deppisch R, Storr M, Buck R, Gohl H. Blood material interactions at the surfaces of membranes in medical applications. Sep Purif Technol. 1998;14:241-54.

23. Cohn LH, Edmunds LH. Cardiac surgery in the adult. New York: McGraw-Hill; 2003. p. 338-48.

24. Chen H, Yuan L, Song W, Wu Z, Li D. Biocompatible polymer materials: role of protein-surface interactions. Prog Polym Sci. 2008;33:1059-87.

25. Houska M, Brynda E, Solovyev A, Broucková A, Krízová P, Vanícková M, Dyr JE. Hemocompatible albumin-heparin coatings prepared by the layer-by-layer technique. The effect of layer ordering on thrombin inhibition and platelet adhesion. J Biomed Mater Res A. 2008;86:769-78.

26. Liu M, Yue XL, Dai ZF, Ma Y, Xing L, Zha ZB, Liu SQ, Li Y. Novel Thrombo-resistant coating based on iron-polysaccharide complex multilayers. ACS Appl Mater Interfaces. 2009;1:113-23.

27. Chen JL, Li QL, Chen JY, Chen C, Huang N. Improving bloodcompatibility of titanium by coating collagen-heparin multilayers. Appl Surf Sci. 2009;255:6894-900.

28. Shu Y, Ou G, Wang L, Zou J, Li Q. Surface modification of titanium with heparin-chitosan multilayers via layer-by-layer self-assembly technique. J Nanomater. 2011;2011:1-8.

29. Lin Q, Yan J, Qiu F, Song X, Fu G, Ji J. Heparin/collagen multilayer as a thromboresistant and endothelial favorable coating for intravascular stent. J Biomed Mater Res A. 2011;96:132-41. 